\title{
Results of unilateral lung volume reduction surgery in patients with distinct heterogeneity of emphysema between lungs
}

\author{
Tommaso C. Mineo, MD \\ Eugenio Pompeo, $\mathrm{MD}^{\mathrm{a}}$ \\ Davide Mineo, $\mathrm{MD}^{\mathrm{a}}$ \\ Paola Rogliani, MDa \\ Carlo Leonardis, MDa \\ Italo Nofroni, BS
}

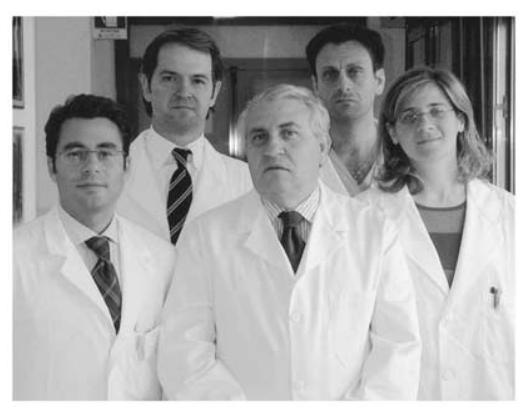

Left to right: Drs D. Mineo, Pompeo, T. Mineo, Leonardis, and Rogliani
Objective: This study was undertaken to analyze the comprehensive outcome of unilateral lung volume reduction in patients with distinct heterogeneity of emphysema between lungs assessed by a visual radiologic scoring system.

Methods: Ninety-seven patients who underwent intentional unilateral lung volume reduction because of distinct heterogeneity of emphysema between lungs (asymmetric ratio of emphysema $\geq 1.1$ ) between 1995 and 2003 were evaluated. Baseline median measures were $0.83 \mathrm{~L}$ for forced expiratory volume in 1 second, $5.0 \mathrm{~L}$ for residual volume, $380 \mathrm{~m}$ for 6-minute walking test distance, 0.50 for maximal incremental treadmill test score, and 25 for physical functioning domain score assessed by the Short Form-36 Quality of Life questionnaire.

Results: Median follow-up was 34 months. Significant improvements occurred for as long as 36 months in forced expiratory volume in 1 second $(+24 \%)$, residual volume $(-12 \%)$, Short Form-36 Quality of Life questionnaire physical functioning domain score $(+100 \%)$, 6-minute walking test distance $(+18 \%)$, and maximal incremental treadmill test score $(+200 \%)$. A direct correlation was found between asymmetric ratio of emphysema and change in forced expiratory volume in 1 second $(r=0.65, P<.00001)$. At 60 months, residual volume $(-6.2 \%)$, maximal incremental treadmill test score $(+100 \%)$, and Short Form-36 Quality of Life questionnaire physical functioning domain score $(+70 \%)$ were still significantly improved. Five-year survival was $82 \%$; 5-year freedom from contralateral lung volume reduction was $70 \%$.

Conclusions: In this series, significant, long-lasting improvements and satisfactory survival were seen after intentional unilateral lung volume reduction. Heterogeneity of emphysema between lungs was directly correlated with improvement at 36 months in forced expiratory volume in 1 second. Our results suggest that unilateral lung volume reduction is a suitable option for patients with distinct heterogeneity of emphysema between lungs.

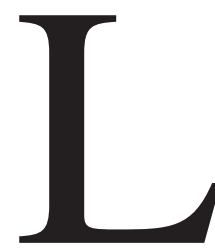

ung volume reduction (LVR) has shown to improve subjective dyspnea, respiratory function, exercise capacity, and quality of life for as long as 5 years for selected patients with severe emphysema. ${ }^{1-3}$ Maximal benefit is achieved when distinct regional difference in tissue destruction (markedly heterogeneous emphysema within lungs) and upper-lobe predominance of disease is identified by visual radiologic scoring systems. ${ }^{4}$ 
LVR can be performed by different techniques and in either unilateral ${ }^{5-8}$ or bilateral ${ }^{1-3}$ fashion. Current consensus is that the best technique is simultaneous bilateral stapling resection, either through a median sternotomy ${ }^{9}$ or by videoassisted thoracoscopic surgery ${ }^{10}$, because of its superior incremental benefit relative to the unilateral approach. ${ }^{11}$ However, Brenner and coworkers ${ }^{12}$ have reported that deterioration in forced expiratory volume in 1 second $\left(\mathrm{FEV}_{1}\right)$ after bilateral LVR was steeper than that after unilateral treatment. Naunheim and colleagues ${ }^{13}$ have reported similar 3-year survivals after unilateral and bilateral LVR. More recently, Goldstein and coworkers ${ }^{14}$ have found no difference in disease specific quality of life changes between patients undergoing bilateral and unilateral LVR. Furthermore, in a previous study ${ }^{15}$ we found that distinct heterogeneity of emphysema between lungs (high asymmetric ratio of emphysema [ARE]) was a predictor of maximal improvement in $\mathrm{FEV}_{1}$, with a positive predictive value of $88 \%$. These controversial findings do not call into question the already defined role of bilateral LVR in patients with bilateral heterogeneous emphysema. Nonetheless, they do suggest that the role of unilateral LVR is yet to be defined and merits further investigation. The aim of this retrospective, single-cohort study was to analyze the comprehensive outcome of sole unilateral thoracoscopic LVR performed intentionally according to precise radiologic morphologic criteria in a tertiary care university-based referral center.

\section{Patients and Methods \\ Patients}

Our LVR surgery program started in October 1995. Through April 2003, a total of 158 patients underwent unilateral $(n=119)$ or one-stage bilateral $(\mathrm{n}=39)$ thoracoscopic LVR. Among unilaterally treated patients, 97 patients undergoing intentional unilateral LVR because of radiologic evidence of distinct heterogeneity of emphysema between lungs were evaluated. After unilateral treatment, contralateral LVR was allowed during follow-up when either the $\mathrm{FEV}_{1}$ returned to the baseline value or the patient became dissatisfied with the functional gain. Data from 14 subjects who underwent staged bilateral LVR were considered in the functional outcome analysis until the last follow-up that preceded the second operation. Conversely, the entire follow-up length was considered for both survival analysis and risk analysis for contralateral treatment.

Patients selected for the operation had emphysema graded radiologically as severe and had significant functional disability despite maximal medical therapy. Eligibility criteria for LVR have been described previously elsewhere ${ }^{16}$ and included postbronchodilator $\mathrm{FEV}_{1}$ less than $40 \%$ predicted, residual volume (RV) more than $180 \%$ predicted, and radiologic evidence of severe emphysema with recognizable target areas for resection. Additional requirement for intentional unilateral LVR was radiologic evidence of distinct heterogeneity of emphysema between lungs. No patient had isolated giant bullous emphysema. All patients were former smokers and had quit smoking at least 4 months before the operation; no patient was homozygous for $\alpha 1$-antitrypsin deficiency.

\section{Physiologic Assessment}

Pulmonary function tests were performed after administration of 2 puffs of aerosolized albuterol (INN salbutamol). Static lung volumes were determined by plethysmography, and diffusing capacity for carbon monoxide was assessed by the single-breath technique. Reference spirometric values were those of the European Respiratory Society. ${ }^{17}$ Exercise tolerance was assessed by standard 6-minute walk test (SMWT) and by maximal incremental treadmill test (MITT). MITT was performed with stepwise increase of both velocity (from $2.7 \mathrm{~km} / \mathrm{h}$ to $6.8 \mathrm{~km} / \mathrm{h}$ ) and gradient (from $0^{\circ}$ to $16^{\circ}$ ) until the symptom-limited maximum was reached, according to 10-stage modified Bruce protocol. Quality of life was assessed with the self-administered Medical Outcomes Study 36-Item Short-Form Health Survey questionnaire (SF-36); the version used was that validated in Italy. ${ }^{18}$

The most severely deconditioned patients were encouraged to undergo a 4-week preoperative rehabilitation program, although this was not an absolute prerequisite. All baseline tests were performed during periods of clinical stability or within 1 week after the completion of a preoperative rehabilitation program. Complete symptomatic, functional, and quality of life assessments were repeated 6 and 12 months after the operation and then yearly. All data were prospectively stored in a database.

\section{Radiologic Assessment}

Radiologic morphologic character of emphysema was assessed according to a previously validated visual scoring system. ${ }^{15}$ Briefly, with high-resolution computed tomography (CT), six standard lung scans obtained from lung apex to base at end-inspiration as reference levels were exactly defined by anatomic structures (brachiocephalic trunk, aortic arch, main pulmonary artery, middle lobe bronchus, ventricular chambers, and $1 \mathrm{~cm}$ above the diaphragm). The following factors were assessed in each lung: (1) The degree of hyperinflation was expressed by the degree of impairment in diaphragmatic excursion estimated in centimeters by superimposing the inspiratory and expiratory posteroanterior chest radiographs with the spine for registration. (2) The severity of emphysema was graded in each CT layer by estimating the percentage of destroyed lung tissue (grade 1 for $0 \%-25 \%$, grade 2 for $25 \%-50 \%$, grade 3 for $50 \%-75 \%$, and grade 4 for $>75 \%$ ). (3) In each lung, the difference between the median severity of emphysema score in the three worst sections and the three best sections was calculated to express the degree of heterogeneity of disease within the lung. (4) The ARE (difference between the lungs) was expressed by the ratio of the higher emphysema severity score to the lower emphysema severity score (Figure 1, $A$ and $B$ ). ARE was also influenced by the regional lung hyperinflation, which was estimated after exclusion of significant scoliosis by measuring the degree of mediastinal switch from the midline. A deviation of at least $1 \mathrm{~cm}$ from the midline in at least two standard CT layers (Figure 1,C) added a score of 0.1 to the ARE.

\section{Surgical Strategy and Technique}

Patients with ARE of at least 1.1 were selected for intentional unilateral LVR. The procedure was directed at reducing the lung volume by excising functionally useless and hyperinflated lung tissue by means of video-assisted thoracoscopic surgery. In typical 


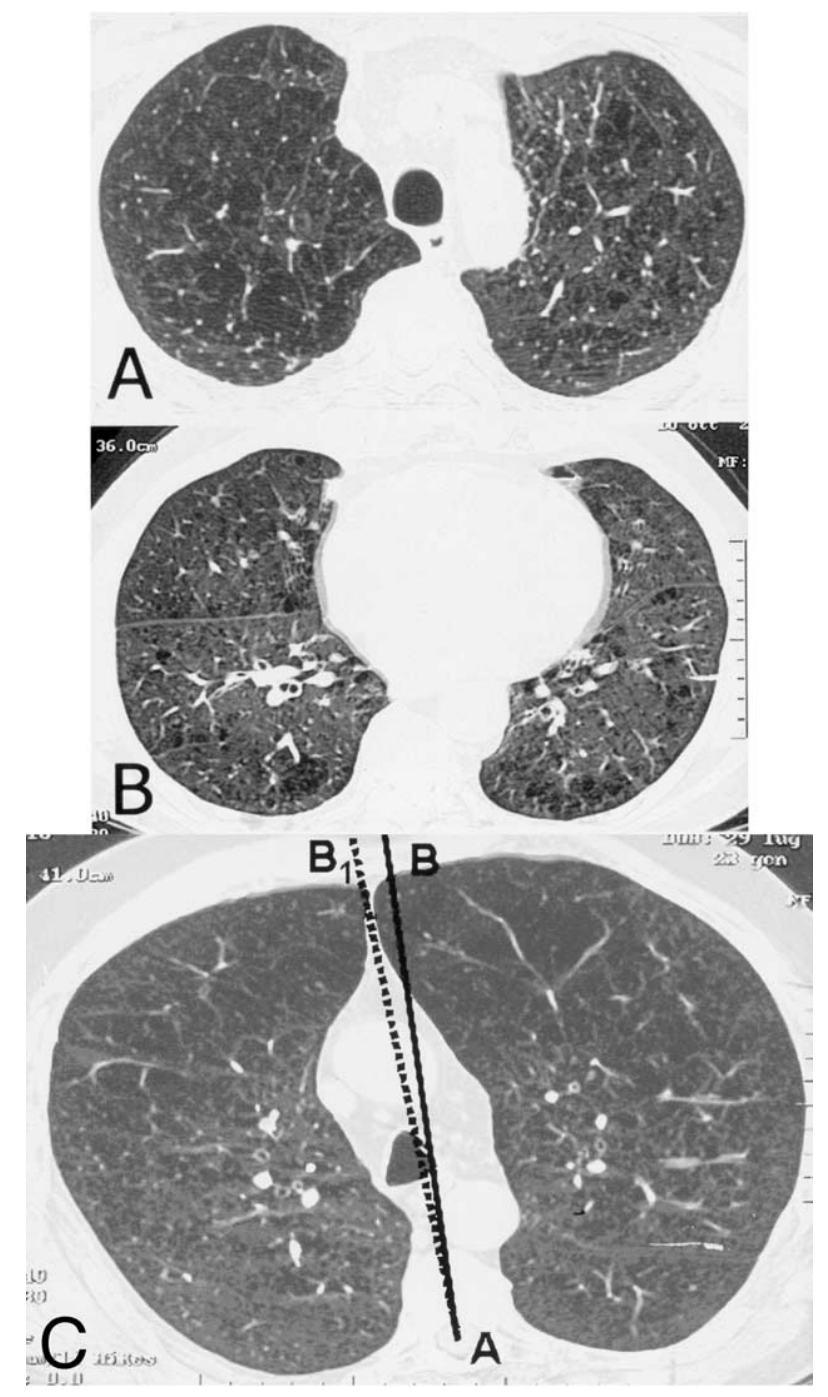

Figure 1. High-resolution CT scan showing distinct heterogeneity between lungs because of more severe emphysematous destruction in right upper lobe. A, Left score of 2 , right score of 3 . B, Left score of 1, right score of 1. ARE of 1.33. C, High-resolution CT scan showing distinct heterogeneity of emphysema between lungs because of more severe regional hyperinflation in left upper lobe causing rightward shift $\left(A B_{1}\right)$ of mediastinum from midline $(A B)$.

upper-lobe prevailing emphysema, staple resection of target areas was performed to excise a reversed U-shaped single strip of emphysematous lung tissue, reducing the upper lobe of about $60 \%$.

\section{Statistics}

Group descriptive statistics are presented as median and interquartile range. The Wilcoxon rank-sum test was used for pair data because of the nonnormal distribution of some data and the small sample size at longest follow-up assessments. Frequencies were compared with a $\chi^{2}$ test or Fisher exact test as appropriate. Correlations were assessed with Spearman correlation coefficients. Survival and risk of contralateral LVR were assessed by the Kaplan-Meier method.
TABLE 1. Radiologic morphologic character of emphysema in the study group

\begin{tabular}{lc}
\hline Upper lobe/middle-lower lobe emphysema (No.) & $95 / 2$ \\
Giant bullae* (No.) & - \\
ARE & 1.28 (1.18-1.38 \\
Patients with ARE $\geq 1.2$ (No.) & 71 \\
Within-lung heterogeneity of disease score & $1.0(1.0-2.0)$ \\
Patients with within-lung heterogeneity score & 89 \\
$\quad \geq 1$ (No.) & \\
Degree of hyperinflation score & $3.0(2.5-3.0)$ \\
Severity of emphysema score & $28(25-33)$ \\
\hline
\end{tabular}

Data are expressed as absolute values or as median values with interquartile ranges.

*Bullae $\geq 7 \mathrm{~cm}$ in maximal size.

\section{Results}

There were 95 men and 2 women, with a median age of 65 years. Assessment of radiologic morphologic character of emphysema is depicted in Table 1. Preoperative rehabilitation was performed by the 13 most deconditioned patients. The 90-day and complete in-hospital mortality in this series was $1.03 \%$ and included 1 patient who died of respiratory failure. The median hospital stay was 9 days, with a range of 4 to 65 days. Median follow-up was 34 months, with no patients unavailable, and ranged from 24 days for the single postoperative death to 85 months. Baseline and postoperative measures of the study group are detailed in Table 2 . Oxygen therapy was required at rest or during exercise by 39 patients before the operation and by 26 of 69 patients at 12 months $(P=.75)$.

\section{Changes in Physiologic Variables}

The FEV 1 and RV showed statistically significant improvements between preoperative values and values at $6,12,36$, and 48 months. Only RV remained improved for as long as 60 months. At 3 years, 17 of 40 evaluated patients (42.5\%) had an improvement in $\mathrm{FEV}_{1}$ of at least $0.2 \mathrm{~L}$; no patients maintained such improvement for at 60 months. Change in $\mathrm{FEV}_{1}$ at 36 months proved directly correlated with ARE (Figure 2), whereas no correlation was found with degree of heterogeneity within the lung $(r=.21, P=.07)$, degree of hyperinflation $(r=.21, P=.18)$, and severity of emphysema $(r=.27, P=.08)$. Diffusion capacity for carbon monoxide had not improved either at 6 months or subsequently. $\mathrm{PaO}_{2}$ was increased significantly at 6 months and remained improved for as long as 12 months. $\mathrm{PCO}_{2}$ averaged $40 \mathrm{~mm} \mathrm{Hg}$ before the operation and had not changed meaningfully as late as 60 months. SMWT and MITT increased acutely and remained improved for as long as 48 months; at 60 months, only MITT remained significantly improved.

\section{Changes in Quality of Life}

Among the eight SF-36 quality of life domains, physical functioning (PF) score was improved for as long as 60 
TABLE 2. Baseline and postoperative data in the study cohort

\begin{tabular}{|c|c|c|c|c|c|}
\hline & \multirow{2}{*}{$\begin{array}{l}\text { Baseline } \\
(n=97)\end{array}$} & \multicolumn{4}{|c|}{ Postoperative } \\
\hline & & $6 \mathrm{mo}(\mathrm{n}=86)$ & 1 y $(n=69)$ & 3 y $(n=40)$ & 5 y $(n=21)$ \\
\hline $\mathrm{FEV}_{1}(\mathrm{~L})$ & $0.83(0.69-1.0)$ & $1.13^{*}(0.98-1.38)$ & $1.10^{*}(0.97-1.40)$ & $1.03^{*}(0.81-1.31)$ & $0.94(0.63-1.22)$ \\
\hline $\mathrm{FEV}_{1}(\%$ predicted $)$ & $27.5(24.2-36.8)$ & $40^{*}(34-48)$ & $39 *(33-47)$ & $35^{*}(28-43)$ & $32(22-41)$ \\
\hline Forced vital capacity (L) & $2.50(2.0-2.8)$ & $3.05^{*}(2.46-3.25)$ & $3.0^{*}(2.45-3.23)$ & $2.9 *(2.4-3.12)$ & $2.80(2.44-3.06)$ \\
\hline Forced vital capacity (\% predicted) & $67(57-77)$ & $83^{*}(68-91)$ & $83^{*}(64-91)$ & $80 *(64-87)$ & $77(62-84)$ \\
\hline $\mathrm{RV}(\mathrm{L})$ & $5.01(4.6-5.7)$ & $4.0^{*}(3.5-4.5)$ & $4.1 *(3.7-4.6)$ & $4.4^{*}(4.0-4.7)$ & $4.7 \dagger(4.5-4.9)$ \\
\hline RV (\% predicted) & $220(195-254)$ & $176^{*}(152-200)$ & $175^{*}(156-204)$ & $187^{*}(174-221)$ & $205 \dagger(192-238)$ \\
\hline $\mathrm{PaO}_{2}(\mathrm{~mm} \mathrm{Hg})$ & $69(65-75)$ & $72^{*}(68-77)$ & $72(69-77)$ & $69(66-75)$ & $68 \ddagger(65-72.5)$ \\
\hline SMWT (m) & $380(350-420)$ & $480 *(430-520)$ & $470 *(450-520)$ & $450 *(425-485)$ & $440(380-470)$ \\
\hline MITT (Bruce class) & $0.50(0.50-1.0)$ & $2.0^{*}(1.0-2.5)$ & $2.0^{*}(1.5-2.5)$ & $1.5^{*}(1.0-2.0)$ & $1.0 \ddagger(0.5-2.0)$ \\
\hline SF-36 PF score & $25(15-40)$ & $50^{*}(45-70)$ & $50 *(50-70)$ & $50 *(45-60)$ & $42.5 \ddagger(27.5-50)$ \\
\hline
\end{tabular}

Data are expressed as median values with interquartile ranges.

$* P<.0002$ versus baseline.

$\dagger P<.003$ versus baseline.

$\ddagger P<.01$ versus baseline.

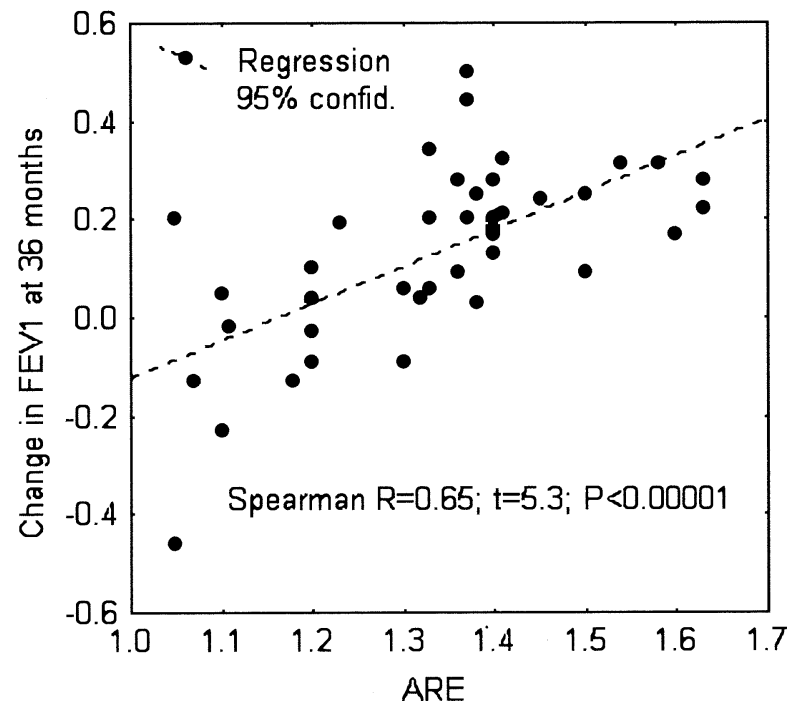

Figure 2. Relationship between ARE and change in FEV 1 at 36 months.

months $(P<.01)$; role physical $(P<.01)$, general health $(P$ $<.01)$, vitality $(P<.01)$, and social functioning $(P<$ .0002) scores were improved for as long as 48 months; and role emotional $(P<.01)$ and mental health $(P<.01)$ scores were improved for as long as 36 months. Overall, an increment in $\mathrm{PF}$ of at least 10 points, which is considered to be clinically significant, was seen at 1,3 , and 5 years in 61 patients (88\%), 34 patients (83\%), and 11 patients (57\%), respectively.

\section{Results in Patients with 5-Year Follow-up}

Because longitudinal analysis with a shrinking cohort is prone to bias, we separately analyzed the results achieved in
21 patients with complete data at all time points through 5 years (Table 3). These results paralleled those achieved in the overall cohort, with significant improvements in $\mathrm{FEV}_{1}$ and SMWT for more than 36 months and in RV, MITT, and SF-36 PF score for more than 60 months.

\section{Risk Analysis for Contralateral LVR and Survival}

At 3 and 5 years, $80 \%$ and $70 \%$ of the patients, respectively, were still free from contralateral treatment (Figure 3, A). At the time of contralateral LVR, 6 patients' $\mathrm{FEV}_{1}$ values had returned to baseline, 4 patients still showed a change in $\mathrm{FEV}_{1}$ between 0.1 and $0.17 \mathrm{~L}$, and the other 4 patients still showed a change in $\mathrm{FEV}_{1}$ between 0.2 and $0.24 \mathrm{~L}$. At most recent follow-up, 12 patients have died of the following causes: respiratory failure $(n=5)$, cancer-related causes $(n$ $=5)$, and cardiac causes $(\mathrm{n}=2)$. The Kaplan-Meier estimates of survival at 60 months and as late as 80 months are shown in Figure 3, B.

\section{Discussion}

Since the pioneering work of Cooper and colleagues, ${ }^{9}$ who proposed simultaneous staple LVR through a median sternotomy, surgically oriented visual scoring systems for radiologic morphologic characteristics of emphysema have been developed to help select candidates for LVR. ${ }^{19-21}$ Results from CT-based qualitative morphologic analyses have shown that distinct heterogeneity of emphysema within the lung, with upper-lobe predominance of disease, is the main predictor of maximal benefit after bilateral LVR.

Our thoracoscopic LVR program started more than 7 years ago, and the surgical strategy that we have since applied was based on some arbitrary and unconventional choices. Unilateral LVR was performed intentionally in patients with distinct heterogeneity of emphysema between 
TABLE 3. Changes in outcome measures for 21 patients with complete data

\begin{tabular}{|c|c|c|c|c|c|}
\hline & \multirow{2}{*}{$\begin{array}{l}\text { Baseline } \\
(\mathrm{n}=97)\end{array}$} & \multicolumn{4}{|c|}{ Postoperative } \\
\hline & & $6 \mathrm{mo}(\mathrm{n}=86)$ & 1 y $(n=69)$ & 3 y $(n=40)$ & 5 y $(n=21)$ \\
\hline $\mathrm{FEV}_{1}(\mathrm{~L})$ & $0.88(0.73-1.10)$ & $1.29 *(1.10-1.58)$ & $1.25^{*}(1.02-1.40)$ & $1.07^{*}(0.85-1.24)$ & $0.94(0.63-1.22)$ \\
\hline $\mathrm{FEV}_{1}(\%$ predicted $)$ & $32(27-40)$ & $43^{*}(39-58)$ & $42^{*}(37-52)$ & $37^{*}(29-46)$ & $32(22-41)$ \\
\hline $\mathrm{RV}(\mathrm{L})$ & $5.0(4.8-5.5)$ & $4.0^{*}(3.8-4.4)$ & $4.1^{*}(3.8-4.4)$ & $4.4^{*}(4.1-4.7)$ & $4.7 \dagger(4.5-4.9)$ \\
\hline RV (\% predicted) & $222(206-243)$ & $187^{*}(161-200)$ & $185^{*}(168-205)$ & $195^{*}(181-221)$ & $206+(192-237)$ \\
\hline SMWT (m) & $400(360-420)$ & $500 *(460-530)$ & $510 *(450-550)$ & $470 *(440-500)$ & $440(380-470)$ \\
\hline MITT (Bruce class) & $1.0(0.50-1.0)$ & $2.0^{*}(1.5-2.5)$ & $2.5^{*}(2.0-3.0)$ & $1.5^{*}(1.0-2.5)$ & $1.0 \ddagger(0.5-2.0)$ \\
\hline SF-36 PF score & $30(25-40)$ & $65^{*}(50-70)$ & $60 *(50-70)$ & $50 *(45-60)$ & $42.5 \ddagger(27.5-50)$ \\
\hline
\end{tabular}

Data are expressed as median values with interquartile ranges.

$* P<.0002$ versus baseline.

$\dagger P<.003$ versus baseline.

$\ddagger P<.01$ versus baseline.

lungs identified and graded through a visual radiologic classification, whereas simultaneous bilateral LVR was preferred in patients with heterogeneous disease within each lung but symmetrically distributed between the lungs.

Initial series on unilateral thoracoscopic LVR resulted in significant improvements in $\mathrm{FEV}_{1}$, RV, dyspnea indices, and SMWT for as long as 12 months. ${ }^{5-8}$ However, these early results were paralleled by those of McKenna and coworkers, ${ }^{11}$ who reported significantly greater improvements in measured spirometry and more frequent relief from oxygen dependence after bilateral LVR than after unilateral treatment. After that report, most surgical investigators switched to the single-stage bilateral approach. Subsequent studies have shown contradictory results, with some surgeons reporting incremental improvements in $\mathrm{FEV}_{1}, \mathrm{PaO}_{2}$, dyspnea relief, SMWT, quality of life, and even survival comparable to those of the bilateral treatment. ${ }^{7,8,13,14}$

The main finding of our study was that postoperative improvements in respiratory function measures, maximal and submaximal exercise capacity tests, and SF-36 quality of life domain scores occurred early after unilateral LVR and lasted more than 36 months. Improvements in SF-36 PF score, RV, and MITT lasted for as long as 60 months. The analysis of relationships between radiologic morphologic factors and change in $\mathrm{FEV}_{1}$ demonstrated the existence of a direct correlation between ARE and change in $\mathrm{FEV}_{1}$ at 36 months, which suggests that for these patients the higher the ARE, the greater the change in $\mathrm{FEV}_{1}$. An other striking feature is that at 60 months $70 \%$ of survivors were still free from contralateral treatment. This suggests that in selected cases unilateral LVR can offer long-lasting benefits, allowing postponement of contralateral treatment for several years.

Acute incremental improvements after unilateral LVR largely exceeded half of those reported on average with bilateral treatment. Becker and associates ${ }^{22}$ measured individual lung volumes by volumetric $\mathrm{CT}$ analysis and showed that unilateral LVR led to an increase in lung volume in the unoperated lung at total lung capacity. A possible explanation is that, because of an interdependence between the lungs, unilateral LVR improves the function of both lungs.

The SF-36 questionnaire has been widely used to investigate the effect of LVR on quality of life, and significant improvements in SF-36 domains have been reported for as long as 60 months, mostly after bilateral treatment. ${ }^{3}$ In our series, many SF-36 domains improved significantly for as long as 48 months, and PF remained improved at 60 months in $57 \%$ of the patients. An almost identical figure was recently reported by Yusen and colleagues, ${ }^{23}$ who found significant clinical changes in PF at 6 months, 3 years, and 5 years in $90 \%, 69 \%$, and $57 \%$ of patients after bilateral LVR, respectively.

Recent results from the National Emphysema Treatment Trial have shown that 3-year survival in patients with upperlobe prevailing emphysema and low baseline exercise capacity was significantly better after surgery than in the medical arm (81\% vs $66 \%) .{ }^{4}$ In our series, $96 \%$ of patients operated on had upper-lobe prevailing emphysema with impaired exercise capacity, although in our analysis the latter was assessed in a different way from the National Emphysema Treatment Trial. Our $82 \%$ 5-year survival compares favorably with both the 69\% 3-year survival after unilateral LVR reported by Naunheim and colleagues ${ }^{16}$ and the $72.6 \%$ 2-year survival after unilateral LVR reported by Serna and colleagues. ${ }^{24}$ This difference may be due to the inclusion of some patients who underwent a staged bilateral LVR and thus could be the most unfit after only unilateral treatment. However, it is worth noting that we found no difference in survival between patients treated with unilateral and staged bilateral LVR (data not shown). One limitation of our study is that we had no routine preoperative rehabilitation program. Rehabilitation is useful to stabilize the clinical condition of the patient and to confirm the decision for surgical intervention. This treatment modality has no effect on respiratory function but can significantly improve exercise tolerance, subjective dyspnea, and quality 


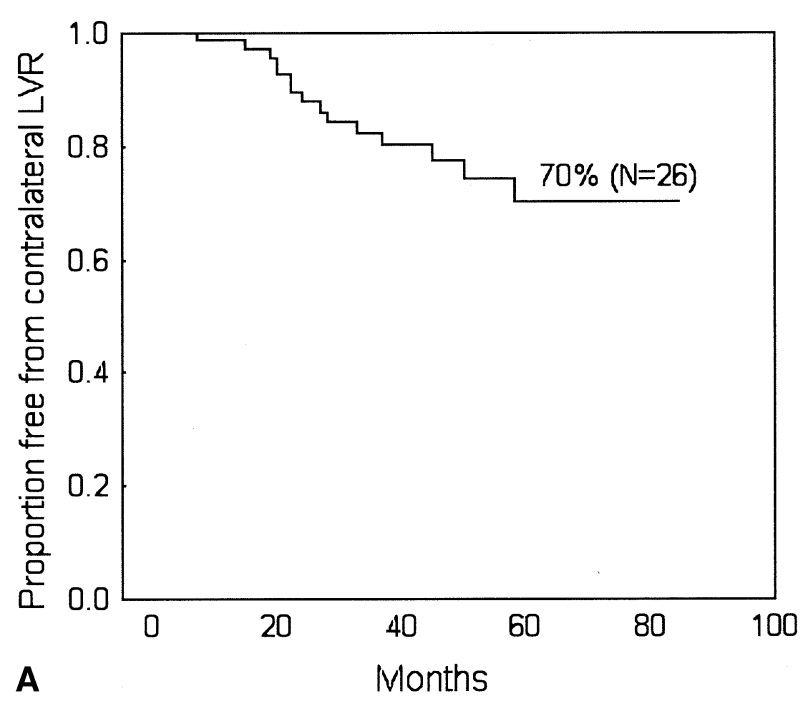

A

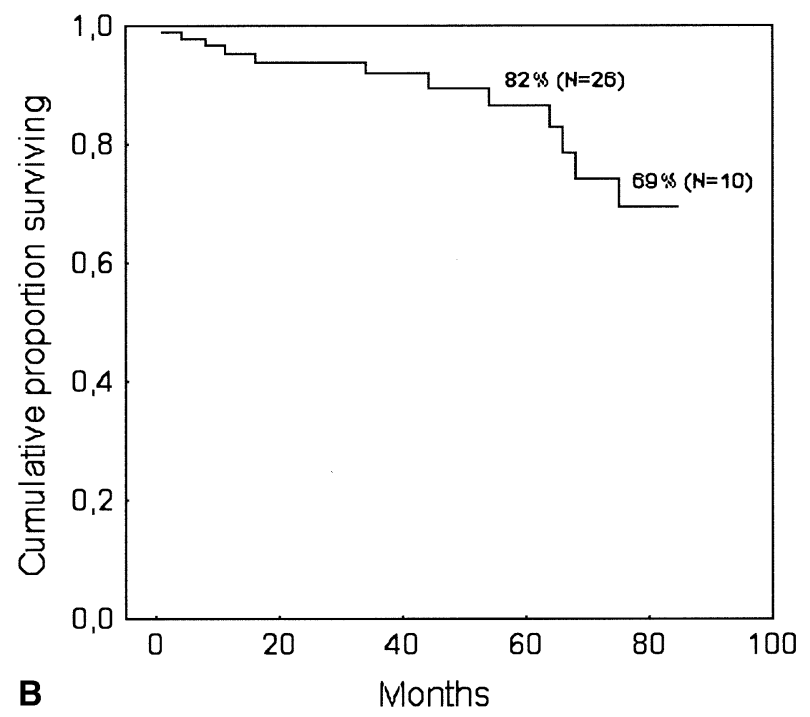

Figure 3. A, Kaplan-Meier curve showing freedom from contralateral LVR. Censored patients at $\mathbf{3 6}$ and $\mathbf{6 0}$ months were $\mathbf{4 6}$ and 26, respectively. B, Kaplan-Meier survival graph showing predicted survival. Censored patients at baseline, 36, 60, and 80 months were $97,46,26$, and 10 , respectively.

of life. ${ }^{25}$ This means that in a worst-case scenario we may have denied many patients some improvements with a potentially increased operative risk. However, we performed rehabilitation in 13 patients considered at increased operative risk, and the extremely low 90-day mortality rate of this series, at the lower end of the range of $0 \%{ }^{10}$ to $28 \%{ }^{26}$ reported in other studies, is encouraging. Finally, the finding that the benefit of rehabilitation is progressively lost within the next 6 months ${ }^{25}$ could also bias the outcome assessment by subtracting presurgical improvements during the early postoperative period.
Our study confirms and extends previous findings indicating that radiologic morphologic character of emphysema plays a key role in the selection of candidates for LVR. Visual scoring systems are less precise than objective quantitative analysis and are subject to some interobserver disagreement. On the other hand, visual scoring systems are simpler and quicker to apply than quantitative analyses and have already proved reliable in selecting candidates for bilateral LVR. ${ }^{4}$ Moreover, with our own visual scoring classification we had already achieved a satisfactory interobserver agreement, with intraclass correlations of 0.95 for the emphysema severity parameter and 0.88 for the ARE. ${ }^{15}$

Lung perfusion scintigraphy also has been used to evaluate candidates for LVR and provides functional information that can be complementary rather than redundant to anatomic imaging studies. ${ }^{27}$ However, when applying a visual semiquantitative scoring system of visual assessment of perfusion scintigrams, correlation between scores of perfusion heterogeneity and functional outcome has been weak. $^{28}$

We believed that to help select candidates for unilateral LVR, CT-based estimation of degree of emphysema heterogeneity and regional hyperinflation is more useful than scintigraphic estimation of degree of perfusion heterogeneity. Our data confirm that our simple and reproducible visual scoring system readily and quite frequently demonstrates marked heterogeneity of emphysema between the lungs (ARE).

In conclusion, satisfactory long-term survival and significant improvements in respiratory function measures, exercise capacity, and health-related quality of life domain scores were seen as late as 60 months in a stringently selected cohort of patients with distinct heterogeneity of emphysema between the lungs undergoing intentional unilateral LVR. These data must be interpreted with caution, and not assumed to mean that one side is better than two. Instead, it seems reasonable to hypothesize that suitable candidates for either unilateral or bilateral LVR can be discriminated by applying simple visual scoring systems that are based on the radiologic morphologic character of emphysema. Further investigation is warranted to eventually confirm, implement, or contradict our findings.

\section{References}

1. Gelb AF, McKenna RJ Jr, Brenner M, Epstein JD, Zamel N. Lung function $5 \mathrm{yr}$ after lung volume reduction surgery for emphysema. Am J Respir Crit Care Med. 2001;163:1562-6.

2. Bloch KE, Georgescu CL, Russi EW, Weder W. Gain and subsequent loss of lung function after lung volume reduction surgery in cases of severe emphysema with different morphologic patterns. $J$ Thorac Cardiovasc Surg. 2002;123:845-54.

3. Ciccone AM, Meyers BF, Guthrie TJ, Davis GE, Yusen RD, Lefrak $\mathrm{SS}$, et al. Long-term outcome of bilateral lung volume reduction in 250 consecutive patients with emphysema. J Thorac Cardiovasc Surg. 2003; $125: 513-25$. 
4. Fishman A, Martinez F, Naunheim K, Piantadosi S, Wise R, Ries A, et al. A randomized trial comparing lung-volume-reduction surgery with medical therapy for severe emphysema. $N$ Engl J Med. 2003;248: 2059-73.

5. Keenan RJ, Landreneau RJ, Sciurba FC, Ferson PF, Holbert JM, Brown ML, et al. Unilateral thoracoscopic surgical approach for diffuse emphysema. J Thorac Cardiovasc Surg. 1996;111:308-16.

6. Naunheim KS, Keller CA, Krucylak PE, Singh A, Ruppel G, Osterloh RN. Unilateral video-assisted thoracic surgical lung reduction. Ann Thorac Surg. 1996;61:1092-2008.

7. Argenziano M, Thomashow B, Jellen PA, Rose EA, Steinglass KM, Ginsburg ME, et al. Functional comparison of unilateral versus bilateral lung volume reduction surgery. Ann Thorac Surg. 1997;64:321-7.

8. Kotloff RM, Tino G, Palevsky HI, Hansen-Flaschen J, Wahl PM, Kaiser LR, et al. Comparison of short-term functional outcomes following unilateral and bilateral lung volume reduction surgery. Chest. 1998; 113:890-5

9. Cooper JD, Trulock EP, Triantafillou AN, Patterson GA, Pohl MS, Deloney PA, et al. Bilateral pneumonectomy (volume reduction) for chronic obstructive pulmonary disease. J Thorac Cardiovasc Surg. 1995;109:106-19.

10. Bingisser R, Zollinger A, Hauser M, Bloch KE, Russi EW, Weder W. Bilateral volume reduction surgery for diffuse emphysema by videoassisted thoracoscopy. J Thorac Cardiovasc Surg. 1996;112:875-82.

11. Mc Kenna RJ Jr, Brenner M, Fischel RJ, Gelb AF. Should lung volume reduction for emphysema be unilateral or bilateral? J Thorac Cardiovasc Surg. 1996;112:1331-9.

12. Brenner M, Mc Kenna RJ Jr, Gelb AF, Fischel RJ, Wilson A. Rate of $\mathrm{FEV}_{1}$ change following lung volume reduction surgery. Chest. 1998; 113:652-9.

13. Naunheim KS, Kaiser LR, Bavaria JE, Hazelrigg SR, Magee M, Landreneau RJ, et al. Long-term survival after thoracoscopic lung volume reduction: a multiinstitutional review. Ann Thorac Surg. 1999; 68:2026-32.

14. Goldstein RS, Todd TR, Guyatt G. Influence of lung volume reduction surgery (LVRS) on health related quality of life in patients with chronic obstructive pulmonary disease. Thorax. 2003;58:405-10.

15. Pompeo E, Sergiacomi G, Nofroni I, Roscetti W, Simonetti G, Mineo TC. Morphologic grading of emphysema is useful in the selection of candidates for unilateral or bilateral reduction pneumoplasty. Eur J Cardiothorac Surg. 2000;17:680-6.

16. Pompeo E, Marino M, Nofroni I, Matteucci G, Mineo TC. Reduction pneumoplasty versus respiratory rehabilitation in severe emphysema: a randomized study. Pulmonary Emphysema Research Group. Ann Thorac Surg. 2000;70:948-54.
17. Quanjer PH, Tammeling GJ, Cotes JE, Pedersen OF, Peslin R, Yernault JC. Lung volumes and forced ventilatory flows. Report Working Party Standardization of Lung Function Tests, European Community for Steel and Coal. Official Statement of the European Respiratory Society. Eur Respir J Suppl. 1993;16:5-40.

18. Apolone G, Mosconi P. The Italian SF-36 Health Survey: translation, validation and norming. J Clin Epidemiol. 1998;51:1025-36.

19. Slone RM, Gierada DS. Radiology of pulmonary emphysema and lung volume reduction surgery. Semin Thorac Cardiovasc Surg. 1996;3:6182 .

20. Weder W, Thurnheer R, Stammberger U, Burge M, Russi EW, Bloch KE. Radiologic emphysema morphology is associated with outcome after surgical lung volume reduction. Ann Thorac Surg. 1997;64:31320.

21. Wisser W, Klepetko W, Kontrus M, Bankier A, Sembaklavaci O, Kaider A, et al. Morphologic grading of the emphysematous lung and its relation to improvement after lung volume resection surgery. Ann Thorac Surg. 1998;65:793-9.

22. Becker MD, Berkmen YM, Austin JH, Mun IK, Romney BM, Rozensthein A, et al. Lung volumes before and after lung volume reduction surgery. Am J Respir Crit Care Med. 1998;157:1593-9.

23. Yusen RD, Lefrak SS, Gierada DS, Davis GE, Meyers BF, Patterson $\mathrm{GA}$, et al. A prospective evaluation of lung volume reduction surgery in 200 consecutive patients. Chest. 2003;123:1026-37.

24. Serna DL, Brenner M, Osann KE, McKenna RJ Jr, Chen JC, Fischel RJ, et al. Survival after unilateral versus bilateral lung volume reduction surgery for emphysema. J Thorac Cardiovasc Surg. 1999;118: 1101-9.

25. Goldstein RS, Gort EH, Stubbing D, Avendano MA, Guyatt GH. Randomised controlled trial of respiratory rehabilitation. Lancet. 1994; 344:1394-7.

26. National Emphysema Treatment Trial Research Group. Patients at high risk of death after lung-volume-reduction surgery. $N$ Engl J Med. 2001;345:1075-83.

27. Kotloff RM, Hansen-Flaschen J, Lipson DA, Tino G, Arcasoy SM, Alavi A, et al. Apical perfusion fraction as a predictor of short-term functional outcome following bilateral lung volume reduction surgery. Chest. 2001;120:1609-15.

28. Thurnheer R, Engel H, Weder W, Stammberger UZ, Laube I, Russi E, et al. Role of lung perfusion scintigraphy in relation to chest computed tomography and pulmonary function in the evaluation of candidates for lung volume reduction surgery. Am J Respir Crit Care Med. 1999;159:301-10. 